\title{
4-Hexylresorcinol inhibits transglutaminase-2 activity and has synergistic effects along with cisplatin in KB cells
}

\author{
SEONG-GON KIM ${ }^{1}$, JAE-HWAN JEONG ${ }^{2}$, YOUNG-WOOK PARK ${ }^{1}$, \\ JI-YOUNG SONG ${ }^{1}$, AN-SOOK KIM ${ }^{1}$, JE-YONG CHOI ${ }^{2}$ and WEON-SIK CHAE ${ }^{3}$ \\ ${ }^{1}$ Department of Oral and Maxillofacial Surgery, College of Dentistry, Gangneung-Wonju National \\ University, Gangneung, 210-702; ${ }^{2}$ Department of Biochemistry and Cell Biology, School of Medicine, \\ Skeletal Diseases Genome Research Center, WCU Program, Kyungpook National University, Daegu, 700- \\ 422; ${ }^{3}$ Gangneung Center, Korea Basic Science Institute, Gangneung 210-702, Republic of Korea
}

Received November 24, 2010; Accepted January 4, 2011

DOI: $10.3892 / o r .2011 .1218$

\begin{abstract}
Resistance to chemotherapy is very important in the prognosis of tumors. Transglutaminase-2 (TG-2) mediated chemotherapy resistance has been widely reported. The objective of this study was to demonstrate the effect of 4-hexylresorcinol (4-HR) on TG-2 activity in nasopharyngeal squamous cell carcinoma cells (KB cells). Treatment with a mixture of 4-HR and cisplatin significantly decreased KB cell viability compared to treatment by cisplatin alone at $10 \mu \mathrm{g} / \mathrm{ml}(\mathrm{p}<0.001)$. 4-HR inhibited TG-2 activity compared to cisplatin alone at 5,10 and $20 \mu \mathrm{g} / \mathrm{ml}(\mathrm{p}=0.001,0.001$ and 0.003 , respectively). Nuclear translocation of TG-2 was also inhibited by 4-HR treatment. 4-HR treatment also increased the fluorescence life-time of DAPI significantly compared to the untreated control or the cisplatin treated group $(\mathrm{p}<0.001)$. In conclusion, 4-HR inhibited TG-2 activity and showed a synergistic effect on tumor cell growth inhibition with cisplatin.
\end{abstract}

\section{Introduction}

Chemotherapy has been done pre- and/ or post-operatively for the treatment of advanced head and neck cancer. However, some head and neck cancers are resistant to chemotherapy via activated nuclear factor- $\kappa \mathrm{B}(\mathrm{NF}-\kappa \mathrm{B})(1)$. In addition, complications after cisplatin containing regimens increase according to the concentration of cisplatin (2). Moreover, it has been shown that there are equal survival rates for advanced head and neck cancers when comparing concurrently chemoradiation therapies to surgical resection (3). Therefore, the

Correspondence to: Dr Seong-Gon Kim, Department of Oral and Maxillofacial Surgery, College of Dentistry, Gangneung-Wonju National University, Gangneung, 210-702, Republic of Korea E-mail: epker@chol.com

Key words: 4-Hexylresorcinol, squamous cell carcinoma, cisplatin, transglutaminase-2 development of a new agent that can decrease the complications of chemotherapy and overcome the resistance that conventional chemotherapeutic agents have is necessary.

Some tumor cells can evade the apoptosis pathway induced by chemotherapy. Transglutaminase-2 (TG-2) is an enzyme with diverse function and may be related to the resistance of chemotherapy agents. TG-2 is overexpressed in many cancers such as breast cancer (4), malignant melanoma (5), and glioblastoma (6). The protein cross-linking activity by TG-2 is related to the resistance of chemotherapy agents (7). It is part of tumor biology because it is involved in the polymerization of the inhibitor of $N F-\kappa B(I-\kappa B)(7)$. The polymerization of $\mathrm{I}-\kappa \mathrm{B}$ can produce many free forms of NF- $\kappa \mathrm{B}$. Therefore, the $N F-\kappa B$ downstream pathway can be activated, and this mechanism is related to tumor cells evading the apoptosis pathway. A tumor showing resistance to cisplatin also has active TG-2 $(5,8)$. Therefore, a TG-2 inhibitor may increase tumor cell death when it is used with cisplatin.

4-Hexylresorcinol (4-HR) is a well known food additive (9). It is a pseudo-tyrosine-like chemical and strong inhibitor of tyrosinase (10). It can inhibit the growth of microorganisms (11). It was used in humans as oral medication in the 1920s for the treatment of typhoid infections (12). Now, it is also the ingredient of oral anti-septics. Oral intake of 4-HR can prevent some types of tumor occurrence in experimental animals (13). The mechanism of tumor inhibition by 4-HR is largely unknown.

In this study, the effect of 4-HR on TG-2 expression in KB cells by fluorescent immunocytochemistry and real-time RT-PCR is presented. The combined effect of cisplatin and 4-HR on KB cell survival was evaluated by MTT assay. The effect of 4-HR on TG-2 activity was evaluated by a commercially available enzyme assay kit. The change of nuclear translocation of transcription factor after administration of 4-HR was evaluated by fluorescence lifetime imaging.

\section{Materials and methods}

Cell cultures and MTT assay. KB cells (human nasopharyngeal carcinoma; ATCC; Manassas, VA, USA) were grown 
to confluence in Ham's F12/Dulbecco's modified Eagle's medium (Gibco, BRL, Gaithersburg, MD, USA) containing $1 \%$ penicillin/streptomycin, fibroblast growth factor-2 $(100 \mu \mathrm{g} / \mathrm{ml})$, and $10 \%$ fetal calf serum (FCS). Cisplatin was added to confluent cells to final concentrations of 1,5 , or $10 \mu \mathrm{g} / \mathrm{ml}$. Cisplatin and 4-HR (Sigma, St. Louis, MO) were mixed together in equal amounts and added to confluent cells to final concentrations of 1,5 , or $10 \mu \mathrm{g} / \mathrm{ml}$.

Quantification of cell viability was assessed after $48 \mathrm{~h}$ of culture growth by tetrazolium salt 3-(4,5-dimethylthiazole-2-yl)-2,5-diphenyltetrazolium bromide (MTT) assay. Briefly, cells were incubated with MTT solution (Cell proliferation kit I; Roche Molecular Biochemicals, Mannheim, Germany) in 6-well plates for $4 \mathrm{~h}$ at room temperature. Formazan crystals were solubilized overnight, and the product was estimated by measuring absorbance at $590 \mathrm{~nm}$ with a Victor Multilabel counter (Perkin-ElmerWallac, Freiburg, Germany).

Fluorescence immunocytochemistry and real-time polymerase chain reaction ( $R T-P C R)$. The antibody for TG-2 was purchased from Santa Cruz Biotechnology (Santa Cruz, CA, USA) for fluorescence immunocytochemistry analysis. Fluorescence immunocytochemistry was done using a previously published method (14). 4',6-Diamidino-2-phenylindole (DAPI) was used for count staining.

For the RT-PCR analysis, KB cells were treated for $12 \mathrm{~h}$ with 4 -HR or cisplatin (5 and $10 \mu \mathrm{g} / \mathrm{ml})$. Total RNA (1 $\mu \mathrm{g})$ was used as a template for first strand cDNA synthesis using the ImProm II Reverse Transcription System (Promega, Madison, WI, USA). RT-PCR for cisplatin treated KB cells was also done using the same method. RT-PCR protocol for TG-1 and TG-2 were done as previously described (15). The primer for TG-1 was GAGAGACCATCCCTATGGCA and GGCAATGTCCTTGCTCATCT (88 bp). The primer for TG-2 was AGCGTTCCTCTTTGCATCCTC and GTAGCTGTTGATAACTGGCTCC (105 bp).

TG-2 enzyme assay. TG-2 was purchased from Sino Biological Inc. (Beijing, China). The TG inhibition assay was done by transglutaminase assay kit (CAT\#CS1070; Sigma). A sample $(25 \mu \mathrm{l})$ containing $1-20 \mu \mathrm{g} / \mathrm{ml}$ of $4-\mathrm{HR}$ or cisplatin was added to a test tube and the sample volume was adjusted to $50 \mu \mathrm{l}$ with enzyme. The mixture was preincubated for $5 \mathrm{~min}$. Each assay mixture was transferred to a single well on a plate. The mixture was incubated on ice for 1-2 $\mathrm{h}$ or at room temperature for 15-30 min. While incubating, $0.1 \mu 1$ of streptavidin-peroxidase solution was diluted into $100 \mu \mathrm{l}$ of phosphate-buffered saline Tween-20 (PBS-T), and this was done for each well. The wells were washed 3 times with ultrapure water. Freshly prepared streptavidin-peroxidase conjugate $(100 \mu \mathrm{l})$ was added to each well and incubated for $20 \mathrm{~min}$ at room temperature. The wells were washed no more than 3 times with $200 \mu \mathrm{l}$ of PBS-T for each well. 3,3',5,5'-Tetramethylbenzidine (TMB) Liquid Substrate System $(200 \mu 1)$ was added to each well. The samples were incubated for 1-3 min at room temperature. The color development was stopped by the addition of $100 \mu \mathrm{l}$ of stop solution to each well. The absorption was read at $450 \mathrm{~nm}$ on a plate reader.

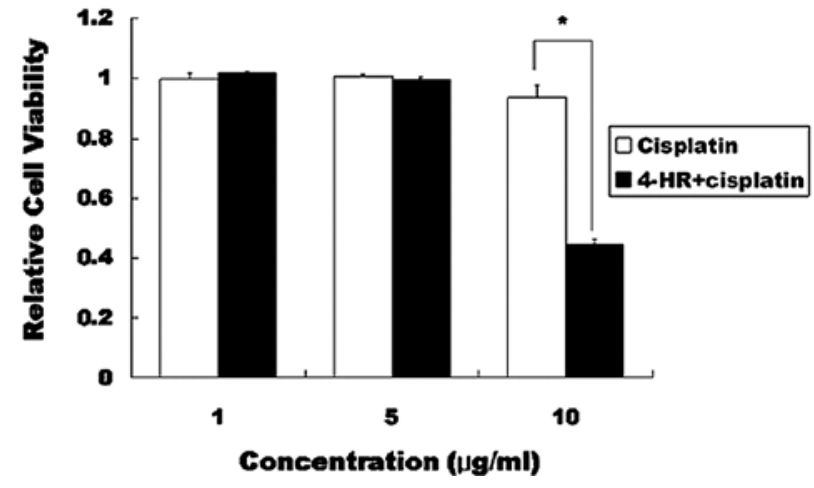

Figure 1. The results of the MTT assay. KB cells were treated for $48 \mathrm{~h}$ by cisplatin or cisplatin or cisplatin + 4-hexylresorcinol (4-HR).

Fluorescence lifetime imaging. Fluorescence lifetime imaging was done using an inverted-type scanning confocal microscope (MicroTime-200, Picoquant, Germany) with a x100 objective $(\mathrm{NA}=1.4)$. A single-mode pulsed diode laser $(375 \mathrm{~nm}$ with an instrumental response function (IRF) of $\sim 240 \mathrm{ps}$ in full-width at half maximum and an average power $<1 \mu \mathrm{W}$ ) was used as an excitation source. A $50-\mu \mathrm{m}$ pinhole and a bandpass filter of $460 \mathrm{~nm}$ (Thorlabs, FB460-10, Newton, NJ, USA) were used to collect emissions from the DAPI stained specimens which were put on a glass cover-slip. The time-resolved fluorescence information was obtained with a time-correlated single-photon counting (TCSPC) technique. The exponential fittings were reformed by an iterative least-squares deconvolution fitting routine. All lifetime values shown in this study were mean intensity-averaged lifetime $\left(\tau_{\text {int }}\right.$. Fluorescence intensity images without lifetime information were simply calculated using the Symphotime software (version 5.1) from the fluorescence lifetime images.

\section{Results}

Synergistic effect of 4-HR and cisplatin on KB cell inhibition. Cell viability of KB cells was tested with cisplatin and 4-HR + cisplatin by MTT assay shown in Fig. 1. The relative cell viability was $1.00 \pm 0.02,1.01 \pm 0.01,0.93 \pm 0.04$ at 1,5 , and $10 \mu \mathrm{g} / \mathrm{ml}$ after treatment with cisplatin for $48 \mathrm{~h}$, respectively. The combined treatment of $4-\mathrm{HR}+$ cisplatin mixture had a relative cell viability of $1.02 \pm 0.01,1.00 \pm 0.01$, $0.45 \pm 0.02$ at 1,5 , and $10 \mu \mathrm{g} / \mathrm{ml}$, respectively. The efficacy of the cisplatin combined with 4-HR compared to cisplatin alone was prominent when the concentration was $10 \mu \mathrm{g} / \mathrm{ml}$ for both the mixture of 4-HR and cisplatin and cisplatin alone $(\mathrm{p}<0.001)$.

4-HR and cisplatin could not inhibit TG-1 and -2 gene transcription, but 4-HR could inhibit TG-2 enzyme activity and its nuclear translocation. The expression of TG-1 increased to $0.96 \pm 0.04$ and $1.89 \pm 0.05$ after the administration of 5 and $10 \mu \mathrm{g} / \mathrm{ml}$ of 4-HR, respectively. Also, the expression of the TG-2 gene increased to $0.71 \pm 0.02$ and $1.18 \pm 0.06$ after the administration of 5 and $10 \mu \mathrm{g} / \mathrm{ml}$ of 4-HR, respectively (Fig. 2A). The expression of the TG-1 gene was $0.72 \pm 0.02$ and $1.19 \pm 0.10$ after the administration of 5 and $10 \mu \mathrm{g} / \mathrm{ml}$ of 
A
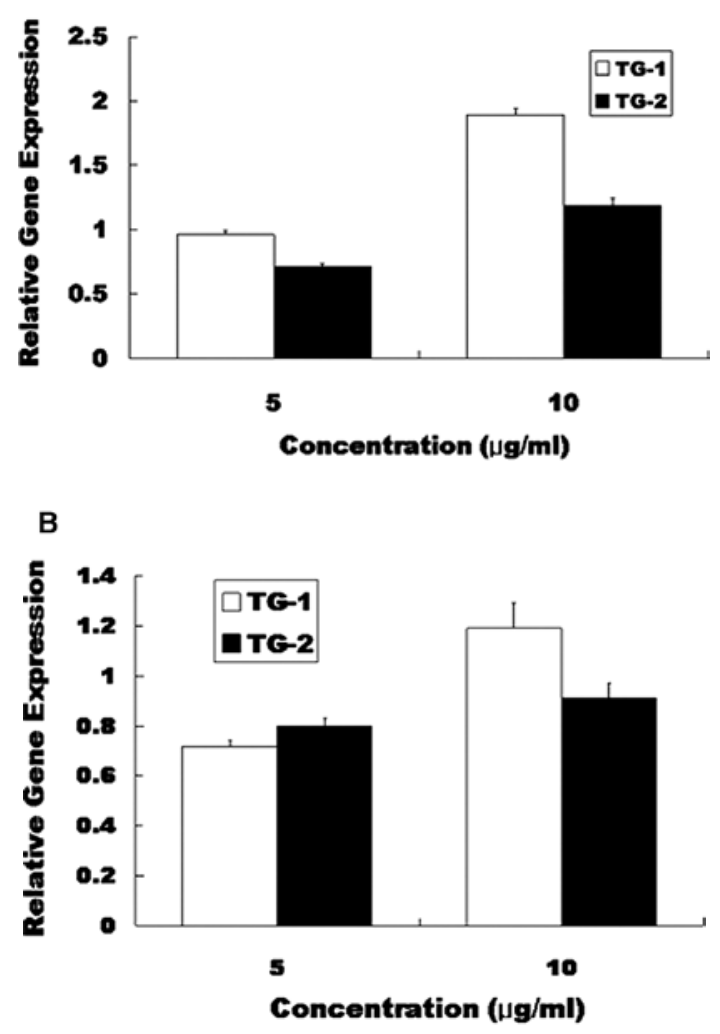

Figure 2. The results of the real-time RT-PCR. (A) 4-Hexylresorcinol treated group; (B) cisplatin treated group.

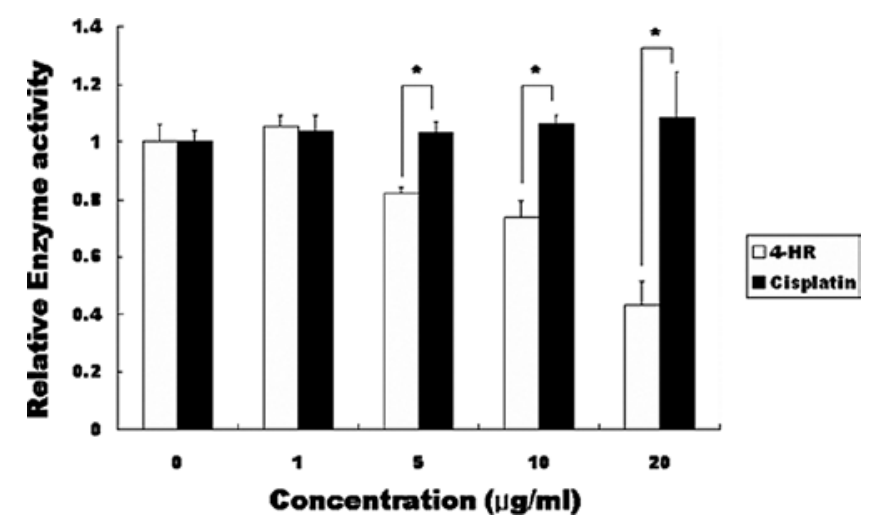

Figure 3. Transglutaminase-2 (TG-2) enzyme assay. Cisplatin did not inhibit TG-2 activity in the tested concentrations (1-20 $\mu \mathrm{g} / \mathrm{ml})$. However, 4-HR inhibited TG-2 activity in a dose-dependent manner $(1-20 \mu \mathrm{g} / \mathrm{ml})$. When comparing the cisplatin treatment and 4-HR treatment, the difference was statistically significant at 5,10 , and $20 \mu \mathrm{g} / \mathrm{ml}(\mathrm{p}=0.001,0.001$, and 0.003 , respectively)

cisplatin, respectively. The expression of the TG-2 gene was $0.80 \pm 0.03$ and $0.91 \pm 0.06$ after the administration of 5 and $10 \mu \mathrm{g} / \mathrm{ml}$ of cisplatin, respectively (Fig. 2B).

Cisplatin did not inhibit TG-2 activity at the tested concentrations (1-20 $\mu \mathrm{g} / \mathrm{ml}$; Fig. 3). However, 4-HR inhibited the TG-2 activity in a dose-dependent manner $(1-20 \mu \mathrm{g} / \mathrm{ml}$; Fig. 3). When comparing the cisplatin treatment to the 4-HR treatment, the difference was statistically significant at 5,
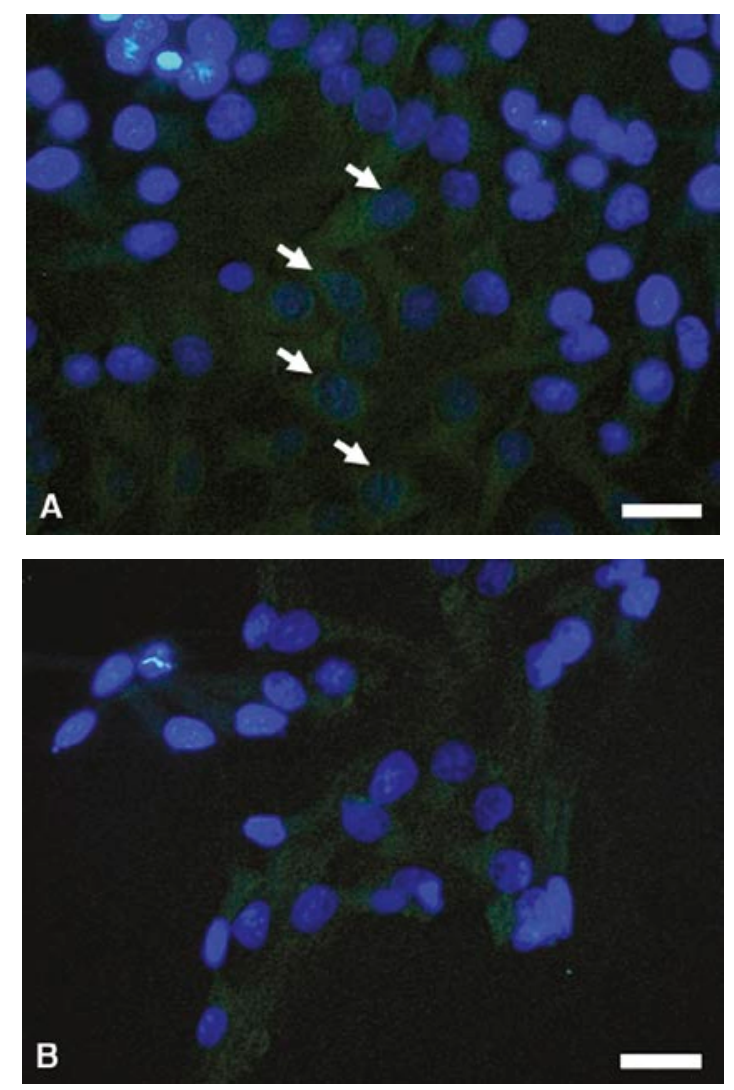

Figure 4. Fluorescence immunocytochemical analyses for the expression of TG-2. TG-2 exhibited nuclear translocation in the untreated control (A). 4-HR inhibited nuclear translocation of TG-2 in the KB cells (B). (Bars, $20 \mu \mathrm{m})$.

10 , and $20 \mu \mathrm{g} / \mathrm{ml}$ ( $\mathrm{p}=0.001,0.001$, and 0.003 , respectively). TG-2 exhibited nuclear translocation in the untreated control (Fig. 4A). 4-HR inhibited nuclear translocation of TG-2 in the KB cells (Fig. 4B).

The observed time-resolved fluorescence decay curves could be reasonably well fitted by two exponential components (Table I). The fluorescence lifetime of DAPI in the nucleus was significantly different in the 4-HR treated groups (Figs. 5 and 6$)$. The intensity weighted average lifetime $\left(\tau_{\text {int }}\right.$ of the control was $1.99 \mathrm{~ns}$ (Fig. 5A), and that of cisplatin was $2.03 \mathrm{~ns}$ (Fig. 5B). The difference between the cisplatin treated group and the no treated control was not statistically significant $(p>0.05)$ and within the error range. However, the fluorescence lifetime of DAPI in the nucleus was significantly different in the 4-HR treated groups (Fig. 5C). The average lifetime of the 4-HR treated group was 2.35 ns (Fig. 5C). It was significantly different to that of the untreated control or the cisplatin treated groups $(\mathrm{p}<0.001)$.

\section{Discussion}

TG-2 facilitates tumor spread and metastasis (16). For example, TG-2 is involved in peritoneal spread of ovarian tumor (17). TG-2 mediated chemotherapy resistance has already been reported (18). TG-2 could be involved in apoptosis in which TG2-dependent cross-linking following increases in intracellular $\mathrm{Ca}^{2+}$ may be important in the stabilization of apoptotic 
Table I. Fluorescence lifetime of the cells including DAPI.

\begin{tabular}{lcccc}
\hline Samples & $\tau_{1}(\%)$ & $\tau_{2}(\%)$ & $<\tau_{\text {int }}>$ & $\chi^{2}$ \\
\hline Control & $0.47 \pm 0.07(44)$ & $2.23 \pm 0.03(56)$ & $1.99 \pm 0.08$ & 1.13 \\
Cisplatin & $0.27 \pm 0.04(49)$ & $2.24 \pm 0.03(51)$ & $2.03 \pm 0.03$ & 1.16 \\
4-HR & $0.28 \pm 0.03(32)$ & $2.46 \pm 0.07(68)$ & $2.35 \pm 0.02$ & 1.15 \\
\hline
\end{tabular}

$\mathrm{I}(\mathrm{t})=\mathrm{A}_{1} \mathrm{e}^{-\mathrm{t} / \tau_{1}}+\mathrm{A}_{2} \mathrm{e}^{-\mathrm{t} / \tau_{2}}$, where $\mathrm{I}(\mathrm{t})$ is the time-dependent fluorescence intensity, $\mathrm{A}$ is the amplitude (noted as the normalized percentage in the parenthesis), and $\tau$ is the lifetime. The excitation and the detection wavelengths are 375 and $460 \pm 5 \mathrm{~nm}$, respectively. Intensity weighted average lifetime, $\left\langle\tau_{\text {int }}\right\rangle$, is defined as $\left\langle\tau_{\text {int }}\right\rangle=\sum_{i} A_{i} \tau_{i}^{2} / \sum_{i} A_{i} \tau_{i}$. 4-HR, 4-hexylresorcinol.
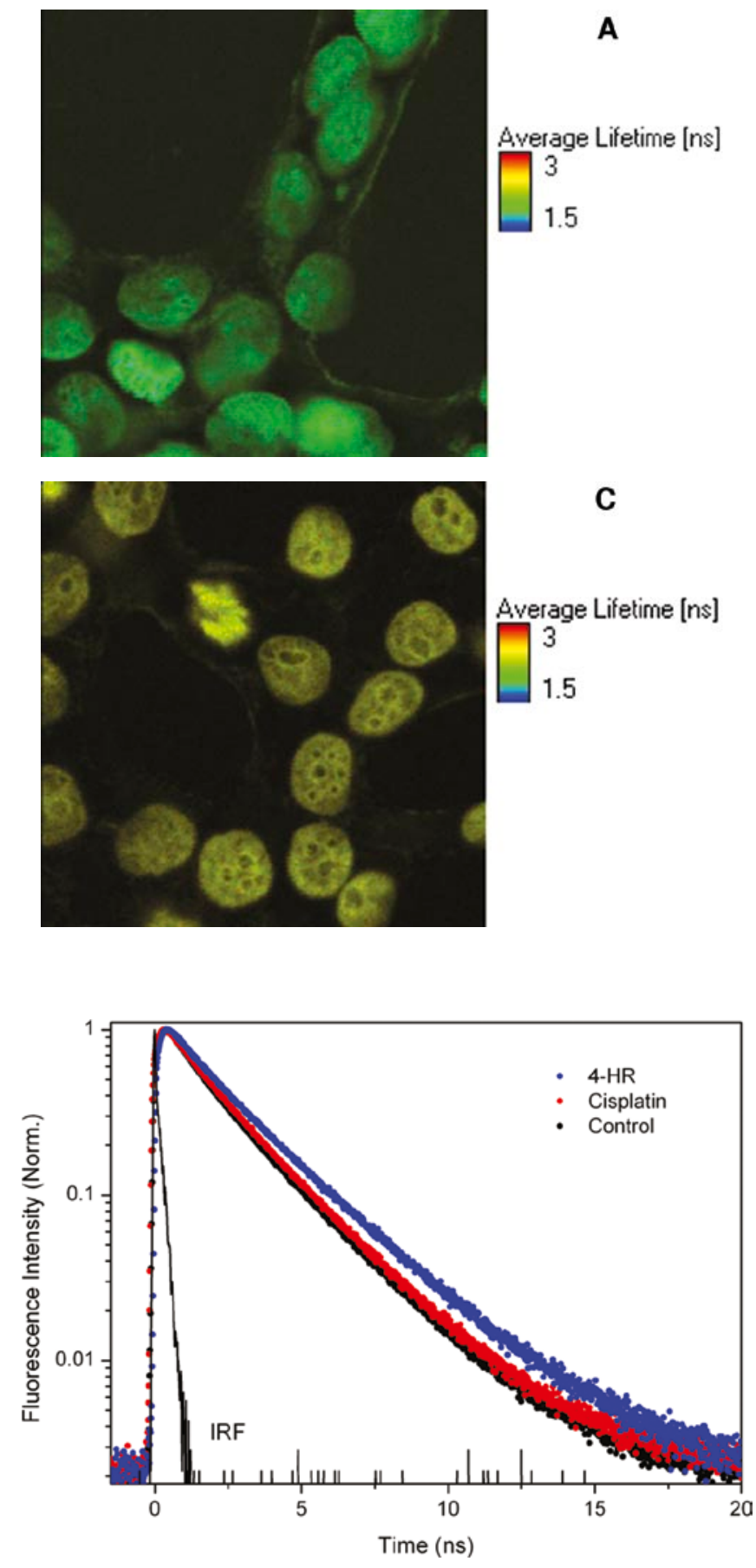

Figure 6. Fluorescence lifetime decays of DAPI treated cells. An instrumental response function (IRF) with a width of $240 \mathrm{ps}$ in full-width at half maximum was also presented.

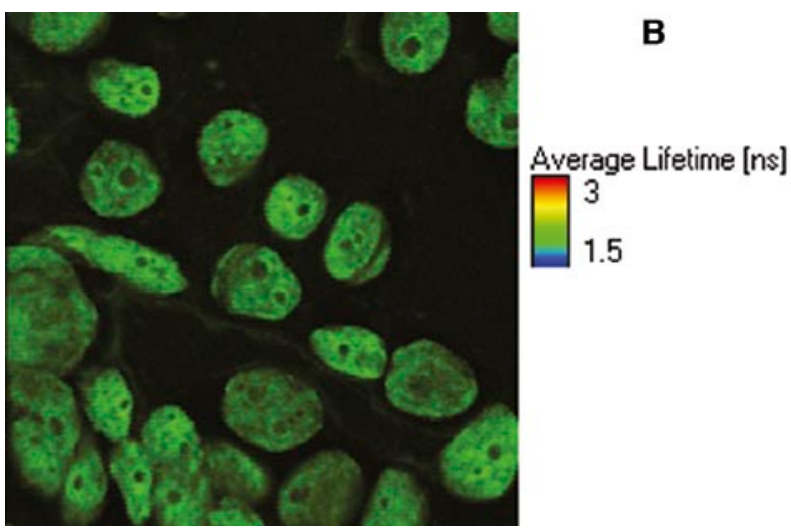

Figure 5. The fluorescence lifetime of DAPI in the nucleus was significantly different in the 4-HR treated groups. The lifetime of the control (A) and that of cisplatin (B) were not different and statistically significant $(\mathrm{p}>0.05)$. However, the lifetime of the 4-HR treated group (C) was different and statistically significant to that of the untreated control or cisplatin alone treated groups $(\mathrm{p}<0.001)$.

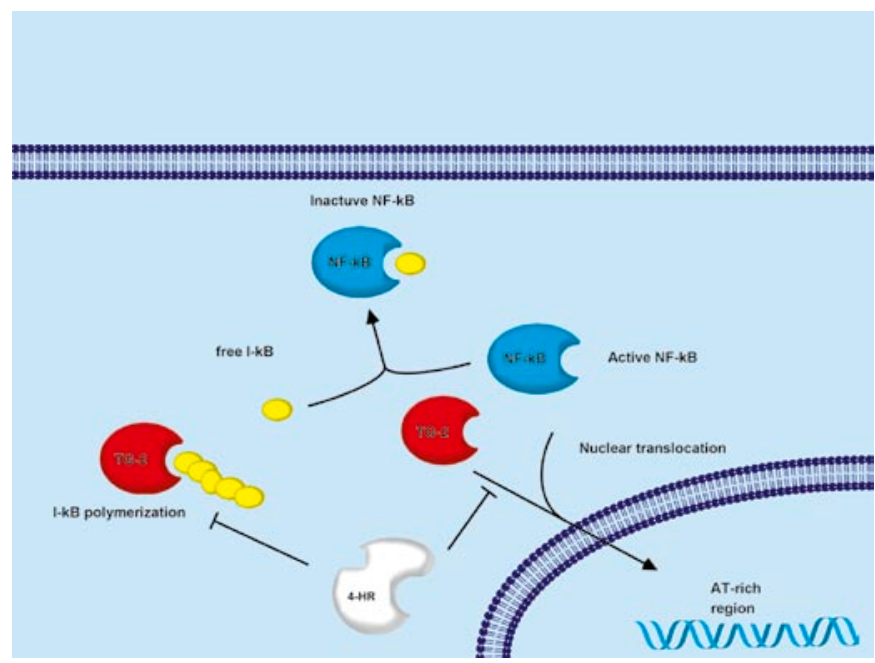

Figure 7. Probable mechanism of $4-\mathrm{HR}$ on TG-2 activity and NF- $\kappa \mathrm{B}$ pathway. 
cells by preventing the loss of intracellular components (19). TG-2 protects ovarian cancer cells from cisplatin induced apoptosis (8). In this study, 4-HR inhibited the TG-2 enzyme activity (Fig. 3). When comparing the mixture containing $5 \mu \mathrm{g} / \mathrm{ml} 4-\mathrm{HR}$ and $5 \mu \mathrm{g} / \mathrm{ml}$ cisplatin to $10 \mu \mathrm{g} / \mathrm{ml}$ of cisplatin alone, the mixture group had a significantly lower tumor cell viability than the cisplatin group $(\mathrm{p}<0.05)$. According to these findings, 4-HR had synergistic effects along with cisplatin on KB cell death.

TG-2 localizes mainly in the cytoplasm, yet recent reports also suggest its presence in the nucleus, mitochondria, at the cell surface, and in the extracellular matrix (20). Nuclear localization of TG-2 is associated with high levels of increased TG activity (21). TG-2 exhibited nuclear translocation in the untreated control (Fig. 4A). 4-HR inhibited nuclear translocation of TG-2 in the KB cells (Fig. 4B). Since 4-HR inhibited TG-2 activity, its nuclear localization may also be inhibited accordingly (Fig. 7). Since 4-HR did not inhibit TG-2 gene expression in KB cells, the inhibition mechanism of 4-HR on TG-2 might be due to direct binding of 4-HR to the TG-2 protein (Fig. 7). Interestingly, 4-HR can bind to tyrosinase directly and inhibits enzyme activity (10).

Pre-incubation with a specific NF- $\mathrm{NB}$ inhibitor blocks $\mathrm{NF}-\kappa \mathrm{B}$ nuclear translocation and reduces glutamate-increased TG-2 expression (22). TG-mediated I- $\kappa \mathrm{B} \alpha$ polymerization can activate NF- $\kappa \mathrm{B}$ directly (23). This agrees with recent reports focusing on the role of TG-2 in preventing cell death depending on the kind of stimuli and cell type (24). NF- $\kappa \mathrm{B}$ binds to AT-rich regions of the promoter in the nucleus (25). DAPI also binds dominantly to AT-rich regions of the DNA in the nucleus (26). If the amount of nuclear NF- $\mathrm{BB}$ is decreased, many AT-rich regions may be available for DAPI binding (Fig. 7). TG-2 is colocalized with the p65 subunit of NF-кB in the cytoplasm, and there is increased nuclear translocation of the p65/TG-2 complex in response to TG-2 activation (27). However, 4-HR may inhibit NF- $\mathrm{KB}$ nuclear translocation via TG-2 inhibition. Actually, 4-HR inhibited TG-2 nuclear translocation (Fig. 4). Then, it may have an influence on DAPI binding to AT-rich regions. In the control and cisplatin treated group, the fluorescence lifetime of DAPI in the nucleus was not significantly different $(\mathrm{p}>0.05)$. However, in the 4-HR treated group, the fluorescence lifetime of DAPI in the nucleus was significant increased compared to the others $(\mathrm{p}<0.001$; Fig. 5). The elongated average lifetime was attributed to the reduced contribution of the shorter lifetime component as well as the elongation and increased contribution of the longer lifetime component (Table I). According to previous studies, a short lifetime component $(0.2<\tau<0.6 \mathrm{~ns})$ was assigned to a proton transfer in the excited state of the DAPI probe, while a long lifetime component $(2.0<\tau<4.0 \mathrm{~ns})$ originated from a tightly bound DAPI-DNA complex $(28,29)$. A relative contribution of a short lifetime component is, therefore, very useful to monitor solvent exposure of a DAPI-DNA complex. From this fluorescence lifetime imaging study, hence, it was considered that the 4-HR treated group was not much affected by the extra-molecular couplings which were plausibly triggered by intruded molecules through a translocation process. If NF- $\mathrm{B}$ can not translocate into the nucleus, free AT-rich regions of DNA in the nucleus may bind to DAPI. Consequently, the fluorescence lifetime of DAPI in the nucleus increased in 4-HR treated groups (Figs. 5 and 6).

In conclusion, 4-HR had a synergistic effect when mixed with cisplatin on KB cells. Since 4-HR is a well known additive for food and has been taken by humans as a medicine in past, its safety to humans is known. Therefore, 4-HR could be a candidate as a chemotherapeutic agent for cisplatin resistant tumors. However, the results of the in vitro study can not be directly extrapolated to clinical applications. Further study must be encouraged for clinical applications.

\section{Acknowledgements}

This study was supported by a grant from the Korea Healthcare Technology R\&D Project, Ministry of Health \& Welfare, Republic of Korea (A080293).

\section{References}

1. Allen CT, Ricker JL, Chen Z and Van Waes C: Role of activated nuclear factor-kappaB in the pathogenesis and therapy of squamous cell carcinoma of the head and neck. Head Neck 29: 959-971, 2007.

2. Cheruku R, Hussain M, Tyrkus $M$ and Edelstein $M$ : Myelodysplastic syndrome after cisplatin therapy. Cancer 72 : 213-218, 1993.

3. Yao M, Epstein JB, Modi BJ, Pytynia KB, Mundt AJ and Feldman LE: Current surgical treatment of squamous cell carcinoma of the head and neck. Oral Oncol 43: 213-223, 2007.

4. Mangala LS, Fok JY, Zorrilla-Calancha IR, et al: Tissue transglutaminase expression promotes cell attachment, invasion and survival in breast cancer cells. Oncogene 26: 2459-2470, 2006.

5. Fok JY, Ekmekcioglu S and Mehta K: Implications of tissue transglutaminase expression in malignant melanoma. Mol Cancer Ther 5: 1493-1503, 2006.

6. Yuan L, Siegel M, Choi K, et al: Transglutaminase 2 inhibitor, KCC009, disrupts fibronectin assembly in the extracellular matrix and sensitizes orthotopic glioblastomas to chemotherapy. Oncogene 26: 2563-2573, 2006.

7. Park KS, Han BG, Lee KH, et al: Depletion of nucleophosmin via transglutaminase 2 cross-linking increases drug resistance in cancer cells. Cancer Lett 274: 201-207, 2009.

8. Cao L, Petrusca DN, Satpathy M, Nakshatri H, Petrache I and Matei D: Tissue transglutaminase protects epithelial ovarian cancer cells from cisplatin induced apoptosis by promoting cell survival signaling. Carcinogenesis 29: 1893-1900, 2008.

9. Guandalini E, Ioppolo A, Mantovani A, Stacchini P and Giovannini C: 4-Hexylresorcinol as inhibitor of shrimp melanosis: efficacy and residues studies; evaluation of possible toxic effect in a human intestinal in vitro model (Caco-2); preliminary safety assessment. Food Addit Contam 15: 171-180, 1998.

10. Arias E, González J, Peiró JM, Oria R and Lopez-Buesa P: Browning prevention by ascorbic acid and 4-hexylresorcinol: different mechanisms of action on polyphenol oxidase in the presence and in the absence of substrates. J Food Sci 72: C464-C470, 2007.

11. Evans RT, Baker PJ, Coburn RA, Fischman SL and Genco RJ: In vitro antiplaque effects of antiseptic phenols. J Periodontol 48: 156-162, 1977.

12. Young CC and Damon SR: Laboratory: the use of hexylresorcinols in the treatment of typhoid carriers. Am J Public Health (NY) 17: 279-280, 1927.

13. Buchholz V, Leuwer M, Ahrens J, Foadi N, Krampfl K and Haeseler G: Topical antiseptics for the treatment of sore throat block voltage-gated neuronal sodium channels in a local anaesthetic-like manner. Naunyn Schmiedebergs Arch Pharmacol 380: 161-168, 2009.

14. Klimentzou P, Drougou A, Fehrenbacher B, et al: Immunocytological and preliminary immunohistochemical studies of prothymosin alpha, a human cancer-associated polypeptide, with a well-characterized polyclonal antibody. J Histochem Cytochem 56: 1023-1031, 2008. 
15. Chen Z, Tong L, Li Z, et al: Hyperosmolarity-induced cornification of human corneal epithelial cells is regulated by JNK MAPK. Invest Ophthalmol Vis Sci 49: 539-549, 2008.

16. Shao M, Cao L, Shen C, et al: Epithelial-to-mesenchymal transition and ovarian tumor progression induced by tissue transglutaminase. Cancer Res 69: 9192-9201, 2009.

17. Satpathy M, Cao L, Pincheira R, et al: Enhanced peritoneal ovarian tumor dissemination by tissue transglutaminase. Cancer Res 67: 7194-7202, 2007.

18. Verma A, Guha S, Wang H, et al: Tissue transglutaminase regulates focal adhesion kinase/AKT activation by modulating PTEN expression in pancreatic cancer cells. Clin Cancer Res 14: 1997-2005, 2008.

19. Fèsus L and Szondy Z: Transglutaminase 2 in the balance of cell death and survival. FEBS Lett 579: 3297-3302, 2005.

20. Piacentini M, Amendola A, Ciccosanti F, et al: Type 2 transglutaminase and cell death. Prog Exp Tumor Res 38: 58-74, 2005.

21. Campisi A, Caccamo D, Raciti G, et al: Glutamate-induced increases in transglutaminase activity in primary cultures of astroglial cells. Brain Res 978: 24-30, 2003.

22. Ientile R, Caccamo D and Griffin M: Tissue transglutaminase and the stress response. Amino Acids 33: 385-394, 2007.
23. Lee J, Kim YS, Choi DH, et al: Transglutaminase 2 induces nuclear factor-kappaB activation via a novel pathway in BV-2 microglia. J Biol Chem 279: 53725-53735, 2004.

24. Fésus L and Szondy Z: Transglutaminase 2 in the balance of cell death and survival. FEBS Lett 579: 3297-3302, 2005.

25. Lee M, Yu S, Lee YS and Park JS: Characterization of nuclear factors binding to AT-rich element in the rat p53 promoter. J Cell Biochem 80: 580-588, 2001.

26. Kubista M, Akerman B and Nordén B: Characterization of interaction between DNA and 4',6-diamidino-2-phenylindole by optical spectroscopy. Biochemistry 26: 4545-4553, 1987.

27. Mann AP, Verma A, Sethi G, et al: Overexpression of tissue transglutaminase leads to constitutive activation of nuclear factor- $\kappa \mathrm{B}$ in cancer cells: delineation of a novel pathway. Cancer Res 66: 8788-8795, 2006.

28. Barcellona ML and Gratton E: The fluorescence properties of a DNA probe. Eur Biophys J 17: 315-323, 1990.

29. Banerjee D and Pal SK: Dynamics in the DNA recognition by DAPI: exploration of the various binding modes. J Phys Chem B 112: 1016-1021, 2008. 